\title{
ASO Visual Abstract: Limited Prognostic Value of KRAS for Patients Undergoing Hepatectomy for Colorectal Liver Metastases
}

\author{
Yoshinori Takeda, MD, $\mathrm{PhD}^{1,2}$, Yoshihiro Mise, MD, $\mathrm{PhD}^{1,2}$, Yu Takahashi, MD, $\mathrm{PhD}^{2}$, Hiromichi Ito, MD, FACS ${ }^{2}$, \\ Yosuke Inoue, $\mathrm{MD}, \mathrm{PhD}^{2}$, Ryuji Yoshioka, $\mathrm{MD}, \mathrm{PhD}^{1}$, Yoshihiro Ono, $\mathrm{MD}, \mathrm{PhD}^{2}$, and Akio Saiura, $\mathrm{MD}, \mathrm{PhD}^{1,2}$ \\ ${ }^{1}$ Department of Hepatobiliary-Pancreatic Surgery, Juntendo University School of Medicine, Hongo, Tokyo, Japan; \\ ${ }^{2}$ Department of Hepatobiliary and Pancreatic Surgery, Cancer Institute Hospital, Japanese Foundation for Cancer Research, \\ Ariake, Tokyo, Japan
}

This multi-center retrospective study showed that the prognostic value of KRAS mutation status after initial hepatectomy for colorectal liver metastases was demonstrated only for patients who received preoperative chemotherapy and those with moderate tumor burden. (h ttps://doi.org/10.1245/s10434-021-11015-9).

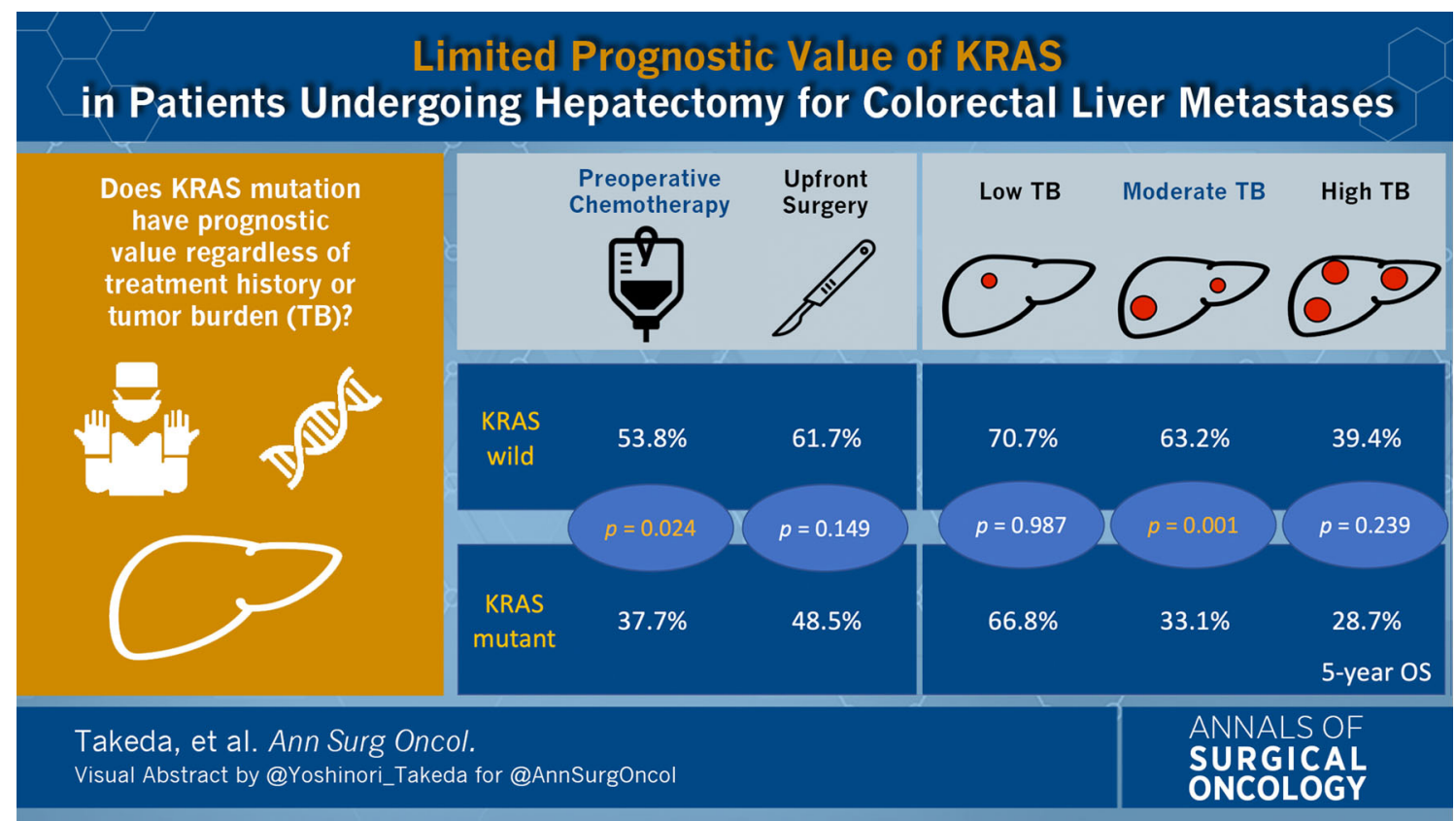

(C) Society of Surgical Oncology 2021

A. Saiura, $\mathrm{MD}, \mathrm{PhD}$

e-mail: a-saiura@juntendo.ac.jp
DISCLOSURES There are no conflicts of interest.

Publisher's Note Springer Nature remains neutral with regard to jurisdictional claims in published maps and institutional affiliations. 